\title{
El género epistolar y la (des)cortesía histórica: estado de la cuestión y reflexión crítica
}

\section{Epistolary genre and historical (im)politeness: state of the art and critical reflection}

\author{
Paula Albitre Lamata \\ Universidad Complutense de Madrid, Madrid, España \\ palbitreaucm.es
}

\section{Resumen}

Este artículo pretende ofrecer una reflexión metodológica acerca de las ventajas que presenta la documentación epistolar en los estudios de pragmática histórica del español y, más específicamente, en el estudio de la (des)cortesía histórica. Asimismo, se describe el estado de la cuestión que presenta actualmente la investigación sobre la (des)cortesía histórica y se realiza un repaso bibliográfico, incluyendo los trabajos más significativos publicados hasta el momento en el mundo hispánico. Finalmente, se apuntan algunas investigaciones que deberán desarrollarse en el futuro para un conocimiento más amplio y completo de la materia.

Palabras clave: pragmática histórica, cortesía histórica, género epistolar, lingüística de corpus, historia de la lengua.

Recibido: 26-03.2020

Aceptado: 20-05-2020

Conflicto de intereses: La autora ha declarado que no posee conflicto de intereses.

Copyright: @ Paula Albitre Lamata. Esta obra está bajo licencia Creative Commons Reconocimiento 4.0.

\begin{abstract}
This paper aims at providing a methodological reflection on the advantages that epistolary documentation presents in studies of Historical Pragmatics of Spanish and, more specifically, in the study of historical (im)politeness. The paper includes a state of the art on historical (im)politeness research and a bibliographic review, which considers the most significant works published to date in the Spanishspeaking world. Moreover, we discuss some research lines that may be developed in the future for a broader and more complete knowledge of the subject.
\end{abstract}

Keywords: historical pragmatics, historical politeness, epistolary genre, corpus linguistics, history of language. 


\section{Pragmática histórica: origen y repaso bibliográfico de los estudios en el mundo hispánico}

El origen de la pragmática histórica, disciplina cuyo objeto de estudio es el uso del lenguaje en contextos pasados (Taavitsainen y Fitzmaurice, 2007, p. 13), es relativamente reciente. Fue en 1985 cuando Stein acuñó el término pragmática histórica en su obra Perspectives on historical pragmatics. Este pionero trabajo proporcionaba una perspectiva sobre distintos aspectos de investigación que podían ser incluidos dentro del campo de esta nueva materia, como las relaciones entre cambios en la lengua y cambios en las estructuras sociales, el estudio histórico de los actos de habla o todo aquello relacionado con la pragmática literaria (Faya Cerqueiro y Vila Carneiro 2014, p. 56).

Ya Cano (1995) insistía en la necesidad, casi exigencia, de interrelacionar lingüística histórica y pragmática para abordar con eficacia estudios sobre el texto, objeto de naturaleza histórico-lingüística. Precisamente el año 1995 será el punto de inflexión de esta nueva disciplina, que adquiere visibilidad e impulso al publicarse la obra Historical Pragmatics (Jucker, 1995), en la que se presenta y propone un marco teórico. Jucker (2008, p. 894) y Brinton (2001, p. 138) coinciden en remarcar la actualidad del surgimiento de la pragmática histórica, pues no será hasta principios de los años noventa cuando, tanto la lingüística histórica como la pragmática lingüística, comiencen a ampliar sus objetos de investigación y a abrir las perspectivas de análisis y estudio, poniendo el foco en los cambios y en el uso del lenguaje en contextos pasados (Jacobs y Jucker, 1995, p. 6).

La pragmática histórica se subdivide a su vez, según Jacobs y Jucker (1995), en dos categorías: la pragmafilología y la pragmática diacrónica. La primera subdisciplina se encarga de estudiar los aspectos contextuales de los textos históricos, incluyendo "las relaciones interpersonales y sociales entre los emisores y sus destinatarios, los factores sociales de la producción y recepción de los textos, así como los propósitos de estos" (Jacobs y Jucker, 1995, p. 11). En paralelo, se desarrolla la pragmática diacrónica, cuya atención se dirige hacia "el inventario lingüístico y sus usos comunicativos a lo largo de las etapas históricas de una misma lengua" (Jacobs y Jucker, 1995, p. 13). Asimismo, esta categoría engloba dos tipologías de estudio distintas, el primer grupo se centra en el desarrollo diacrónico de la lengua en uso, incluyendo también descripciones sincrónicas; mientras que el segundo grupo dirige su foco hacia los principios comunicativos y los factores pragmático-discursivos que producen cambios en la lengua (Cruz Volio, 2017, p. 19).

\subsection{Estudios generales de la pragmática histórica del español}

Ciertamente, la anglística y la germanística presentan una mayor tradición, respecto a la romanística, en materia de investigación diacrónica de la pragmática. La romanística se ha inclinado hacia el estudio de los actos de habla, primero desde una perspectiva sincrónica, para después desviar paulatinamente su interés hacia lo diacrónico. Los objetivos de esta subdisciplina de la Pragmática histórica son realizar un inventario y una descripción de las formas lingüísticas empleadas para realizar distintos actos de habla en las distintas épocas y explicar tanto las condiciones (sociales, culturales y discursivas) de su uso, como los cambios sufridos por unas y otros (Iglesias Recuero, 2016, p. 973). Otras tendencias destacables de la pragmática histórica son, como recoge (Cruz Volio, 2017, p. 21), los estudios sobre formas dialogales y su tratamiento en textos literarios, los trabajos 
que indagan sobre el papel de las tradiciones discursivas como modelos en la producción textual y, por último, el análisis de los sistemas de tratamiento en las distintas épocas.

El ámbito de investigación hispánico no ha sido ajeno al desarrollo de la pragmática histórica. La publicación de interesantes trabajos sobre aspectos históricos del discurso en los últimos veinte años da fe de este reciente progreso. De hecho, antes de esta proliferación de publicaciones, fueron varias las personalidades que apuntaron la necesidad del desarrollo de estudios pragmáticos históricos del español (Bustos Tovar, 2000; Ridruejo, 2007, entre otros).

Revisando los estudios previos de la pragmática histórica hispánica, se pueden observar dos corrientes de investigación en función de la tipología de las fuentes documentales que conforman el corpus de trabajo: textos no literarios y literarios.

Entre los trabajos del primer grupo, destacan los estudios sobre las formas de tratamiento en cartas de emigrantes del siglo XVI (Bentivoglio, 2003), en cartas coloniales entre la metrópoli y colonias del siglo XVIII (Bravo García, 2004), en textos jurídico-administrativos del siglo XVI (Carrera de la Red y Álvarez, 2004) o en textos periodísticos (Carrera de la Red, 2012) y los trabajos sobre los actos directivos en documentos jurídicos indianos (Wesch, 1996, sobre el siglo XVI; Carrera de la Red y Herrán Santiago, 2007, sobre el siglo XVIII), en quejas de los siglos XVI y XIX (Pons y Octavio de Toledo, 2016) y en cartas familiares del siglo XVI (King, 2010b). Estas publicaciones parten del principio según el cual la alternancia de los tratamientos y la cortesía trasciende lo puramente social para instalarse en lo situacional y pragmático. Asimismo, profundizan en las explicaciones pragmáticas que tienen que ver con la intención de los hablantes y las relaciones de distancia, poder y solidaridad (Brown y Gilman, 1960) entre los participantes del discurso en las distintas tipologías textuales analizadas.

Dentro de las investigaciones con fuentes literarias, existe, a su vez, una vertiente de publicaciones sobre el género dramático y otra sobre el género épiconovelesco. Las características intrínsecas de estos textos literarios, con la consiguiente pretensión estilística de sus autores, permiten la representación detallada del estilo de vida contemporáneo, por lo que constituyen un corpus excepcional para el estudio histórico de fenómenos de la pragmática.

El empleo de obras de teatro como base de datos ha generado importantes trabajos dentro de la pragmática histórica, entre los que señalamos los realizados sobre fórmulas de tratamiento, atendiendo fundamentalmente a cuestiones pragmáticas como los contextos y las situaciones (Navarro Gala, 2004, en La Segunda Celestina; Pedroviejo Esteruelas, 2004, en Bajarse al moro e Historia de una escalera; Hamad Zahonero, 2015, en varios textos dramáticos del siglo XVI ${ }^{1}$ ), sobre la evolución de la imagen del rol familiar (Gancedo Ruiz, 2018, 2019; obras de finales del siglo XIX a mitad del XX) y sobre la conformación de la (des)cortesía, en concreto sobre la historia de la formulación de actos de habla (Moreno González 2002, 2008; Iglesias Recuero, 2010; King, 2012).

También han resultado fructíferas las investigaciones sobre la ficción épiconovelesca en español, pues no solo han aportado conocimientos sobre la

\footnotetext{
${ }^{1}$ Égloga de Plácida y Vitoriano de Juan del Encina, Penitencia de amor de Pedro Manuel Ximénez de Urrea, Comedia Himenea de Bartolomé de Torres Naharro, Tragicomedia de Don Duardos de Gil Vicente, Segunda Celestina de Feliciano de Silva y Pasos de Lope de Rueda.
} 
configuración de las preguntas en la épica medieval (Schroot, 2000) o sobre el sistema de tratamiento en las novelas de los siglos XVI y XVII (Rígano, 2000; García Aguilar, 2012); sino que son varios los estudios que han contribuido específicamente al análisis diacrónico de la (des)cortesía, desde la época medieval hasta el siglo XX (Haverkate, 2001; Herrero Ruiz de Loizaga, 1999, 2007 y 2013; Moreno González, 2008; Iglesias Recuero, 2016; Leal Abad, 2008 y 2011; Zamora, 2014 y Cruz Volio, 2017).

Pese a que en el panorama nacional la pragmática histórica ha sufrido un notable desarrollo en los últimos años, como reflejan los interesantes trabajos mencionados fruto de su madurez metodológica, aún permanece a la sombra de los estudios pragmáticos sobre lengua actual.

\subsection{Estudios específicos de la (des)cortesía histórica del español}

El estudio histórico de la (des)cortesía, siguiendo las líneas de la propia pragmática, se desarrolló inicialmente en el ámbito inglés (Elias, 1994; Jucker,1995; Muir, 1997; Bax y Kádár, 2012; Jucker y Taavitsainen, 2010; Taavitsainen et al., 2015 y Jucker y Kopaczyck, 2017). Estos trabajos han incidido en la visión sociocultural y discursiva no solo de los usos lingüísticos, sino también de la concepción de la (des)cortesía y de los parámetros sociopragmáticos que se emplean para su explicación y descripción.

Desde la publicación de La cortesía verbal (1994) de Haverkate, la investigación de la (des)cortesía verbal en diversas variedades del español, englobando las perspectivas sociolingüística y sincrónica, se ha multiplicado ${ }^{2}$. Esta situación muestra un creciente interés hacia la pragmática desde el mundo hispánico, en contraposición, aun resultan insuficientes las investigaciones que indagan sobre su manifestación histórica.

El incremento del interés diacrónico desde la pragmática se debe, en parte, a la reconsideración tanto de las fuentes válidas de estudio como de la misma teoría de la (des)cortesía verbal en los enfoques posmodernos o discursivos, desde los cuales se ha intentado indagar en el funcionamiento de este fenómeno en estadios previos de la lengua. Asimismo, optar por una dimensión histórica permite profundizar en las teorías cortesiológicas, en tanto que sirve para valorar críticamente ciertos presupuestos, como los de la universalidad y racionalidad (Cruz Volio, 2017, p. 15) y para profundizar sobre lo que ya se ha investigado en estadios actuales de la lengua. Partimos de dos supuestos inversos, el primero sugiere que el

\footnotetext{
${ }^{2}$ Este impulso hacia el estudio de la expresión verbal de la (des)cortesía en español se expresa en el número creciente de publicaciones sobre este tema, por lo que encontramos distintas perspectivas. La relación entre cortesía y marcadores del discurso en español ha sido uno de los campos más estudiados, destacando los trabajos de Iglesias Recuero (2001), Martín Zorraquino (2001) o Landone (2009a). También se han realizado numerosas investigaciones contrastivas sobre la relación existente entre la cortesía y la cultura. En este ámbito podemos situar trabajos de contraste intercultural como los de Bravo y Briz (2004) o Sánchez Castro (2007). Desde el enfoque sociodialectal, autores como Placencia y García (2001), Murillo (2005) o Bolívar (2010) centran sus investigaciones en aspectos concretos de la cortesía en distintas variedades del español americano. Una de las perspectivas más fructíferas es la que el papel de la cortesía verbal en el aula de ELE (Español como Lengua Extranjera); autores como Alonso Raya (1998), Alonso-Cortés et al. (2001), Gutiérrez Ordóñez (2006), García Vizcaíno (2008), Pérez-Cordón (2008), Níkleva (2009), Landone (2009b) o Fuentes Rodríguez (2010) confirman la necesidad de incluir la competencia pragmática en las aulas. Asimismo, es necesario resaltar el aporte de dos grupos de investigación al estudio de la cortesía en español:

1. Grupo Val.Es.Co (Universidad de Valencia, 1990), profundiza en el fenómeno de la cortesía en la conversación coloquial española y en las herramientas lingüísticas asociadas a él.

2. Programa EDICE (Universidad de Estocolmo, 2001), conforma uno de los referentes más relevantes en cuanto a estudios de cortesía en el mundo hispanohablante.
} 
conocimiento histórico resulta preceptivo para interpretar adecuadamente los procesos de variación y cambio sincrónico (Blas Arroyo, 2019, p. 10); el segundo defiende que los hechos del presente pueden ayudarnos a explicar el pasado (Labov, [1983] 1972).

Aunque presente y pasado estén relacionados, la aplicación directa en estudios históricos de patrones y resultados obtenidos en investigaciones actuales no es totalmente adecuada. No es posible inferir cambios pasados a partir exclusivamente de la observación del presente, pues puede que estos no estén condicionados por los mismos factores lingüísticos y extralingüísticos que los fenómenos de variación actuales. En consecuencia, los estudios históricos deben desarrollar sus propios principios metodológicos para así atender debidamente a las modificaciones y cambios de cada época.

La escasez de estudios sobre (des)cortesía histórica y formulación de actos de habla, en comparación con los realizados desde una perspectiva sincrónica $u$ otros ámbitos de la pragmática histórica, como las formas de tratamiento ${ }^{3}$, refleja la inexistencia de métodos de investigación apropiados para abordar este fenómeno. En las últimas décadas ha comenzado a publicarse una cantidad notable de trabajos en los que se estudia específicamente la cortesía de etapas previas del español, lo que constata la profusión de la pragmática histórica como disciplina de estudio filológico. A pesar del gran avance en la delimitación teórica y el desarrollo metodológico de esta disciplina, como avalan los significativos trabajos expuestos en el epígrafe anterior, todavía es necesario llevar a cabo una reflexión teórica sobre los principios tradicionales de la (des)cortesía, que contribuya a su reevaluación metodológica y permita arrojar luz y aclarar dudas sobre su estudio diacrónico.

Los recientes estudios sobre la historicidad de la cortesía, en aumento desde 2010, tienen como objetivo no solo lograr el nivel de los trabajos sincrónicos, sino reconceptualizar la teoría de la (des)cortesía verbal. Investigaciones importantes sobre la (des)cortesía histórica, dentro de la romanística, son los estudios de Held (2005a, 2010) acerca de la expresión de la cortesía verbal en la tradición discursiva epistolar italiana de la Edad Media, Rouvillois (2008) sobre las distintas evaluaciones de las expresiones de cortesía en francés desde 1789 hasta hoy o la monografía de Frank (2011) sobre actos de habla directivos franceses, desde el siglo $\mathrm{XI}$ a nuestros días.

Dentro del ámbito del español, los estudios sobre la (des)cortesía realizados desde una perspectiva diacrónica también han adquirido un papel preponderante en las últimas décadas, destacando los de Wesch (1996), Schrott (2000), Haverkate (2001), Moreno González (2002, 2008), Carrera de la Red y Álvarez (2004), Herrero Ruiz de Loizaga (1999, 2007 y 2013); King (2010b y 2012), Bustos Gisbert (2007), Bustos Gisbert e Iglesias Recuero (2003), Iglesias Recuero (2010, 2016, 2017 y en prensa), Carrera de la Red (2013), Leal Abad (2011), Zamora (2014), Cruz Volio (2017), Gancedo Ruiz (2018 y 2019), Martínez Pasamar (2019), Martínez Pasamar y Tabernero Sala (2019), Tabernero Sala (2010, 2019), Albitre Lamata (2019) y Bello Hernández (2019).

\footnotetext{
${ }^{3}$ Los trabajos, tanto con fuentes literarias como no literarias, dedicados a la historia de los tratamientos son incontables, no solo desde un acercamiento pragmático y sociolingüístico, sino también con interés en su sintaxis, morfología o léxico: Herrero Ruiz de Loizaga, 1999, García Mouton, 1999b; Lapesa, 2000; Eberenz, 2000; Calderón Campos, 2001, 2003, 2006, 2009 y 2010; Bustos Gisbert e Iglesias Recuero, 2003; Bentivoglio, 2003; Pedroviejo Esteruelas, 2003 y 2012; Medina Morales, 2004 y 2012; Pountain, 2009; Hammermüller, 2010; King, 2010a o Bustos Gisbert, 2016, entre otros.
} 
La gran parte de estos trabajos toma como documentos de estudio textos literarios, salvando los de Carrera de la Red y Álvarez (2004), que estudian la cortesía de los tratamientos nominales en documentos venezolanos del siglo XVI; Wesch (1996), que analiza la conformación de ordenanzas e instrucciones en documentos jurídicos indianos del siglo XVI; King (2010b, 2012), cuyo foco de análisis son los actos directivos en cartas familiares de los siglos XVI y XVII; Tabernero Sala (2010), que se centra en la expresión de la descortesía en textos jurídicos del siglo XVIII; Carrera de la Red (2013), que presenta un análisis de la intensificación y la atenuación en textos administrativos colombianos del siglo XVIII; Iglesias Recuero (2017), que realiza un estudio sobre atenuación de las peticiones en cartas privadas del siglo XVI, y Albitre Lamata (2019), cuya investigación se centra en los mecanismos de cortesía en cartas privadas del siglo XVI. Además, en los últimos dos años, varios trabajos (Martínez Pasamar, 2019; Martínez Pasamar y Tabernero Sala, 2019; Tabernero Sala, 2019) han reflexionado sobre el tratamiento de la atenuación y la intensificación y su variación en corpus epistolares del siglo XIX.

La teoría de la cortesía verbal de Brown y Levinson (1978) ha constituido el eje central de gran parte de las investigaciones, dedicadas a interpretarla, modificarla o incluso refutarla. Haverkate (2001) toma como modelo esta propuesta para analizar las estrategias de cortesía, tanto positiva como negativa, generadas en los diálogos entre Don Quijote y Sancho Panza. Tras profundizar en la representación de la imagen positiva (actos realizativos, argumentativos y expresivos) y de la imagen negativa (actos exhorativos) en los diálogos seleccionados, Haverkate (2001, p. 146) constata una extrapolación de la jerarquía social a los usos lingüísticos y expresiones de la cortesía, orientados a la protección y fortalecimiento de la imagen de Don Quijote como caballero andante y autoridad.

El estudio de la cortesía verbal vinculada a los sistemas de tratamiento ha sido el foco de varios trabajos (Herrero Ruiz de Loizaga, 1999; Bustos Gisbert e Iglesias Recuero, 2003; Bravo García, 2004; Bustos Gisbert, 2007; Bello Hernández, 2019). Los tratamientos, según Levinson (1983, p. 80), codifican la identidad de los participantes y la relación entre ellos al pertenecer al ámbito de la deixis social, por lo que cumplen una función fundamental en la manifestación de la cortesía y de los valores culturales definidores de las comunidades. En publicaciones recientes, como indica Herrero Ruiz de Loizaga (1999, p. 222), el estudio de los tratamientos se ha abordado desde una perspectiva integradora junto a las estrategias de cortesía que los provocan, confluyendo de esta forma los estudios de tratamiento y los de cortesía. No en vano, determinados pronombres aparecen codificados en muchas lenguas dentro del propio sistema gramatical, a partir de las relaciones sociales e interpersonales que los hablantes mantienen entre sí. A través de estas publicaciones se ha podido constatar que la variación pronominal se halla fuertemente condicionada por diversos factores sociales como la edad, el sexo, la clase social o el nivel educativo, así como por otros de carácter discursivo, como la modalidad y el tipo de formalidad de la interacción, las relaciones de poder/solidaridad entre los hablantes (Brown y Gilman, 1960) o las estrategias mismas de cortesía.

Un número notable de investigaciones se ha interesado específicamente por la historia de actos de habla en español. Moreno González (2002) defiende la validez de investigar textos dramáticos antiguos desde una perspectiva pragmática y sociolingüística y centra su estudio en actos de habla directivos de principios del 
siglo XVII. Para esta investigación, los datos se extraen de un corpus constituido por obras del género dramático español (cinco entremeses de Cervantes y El castigo sin venganza de Lope de Vega), con el fin de conseguir variedad de toda la escala social del momento, distinguiendo dos grupos: privilegiados y no privilegiados. $\mathrm{La}$ autora clasifica los actos directivos del corpus en función de una escala con dos polos, directo-indirecto, y afianza la noción de correlación entre el grado de direccionalidad del acto y el estatus social del hablante. Así, los usos directos expresan cercanía e igualdad entre interlocutores iguales (principio de solidaridad; Brown y Gilman, 1960); mientras que, en el caso de las interacciones entre participantes de distintos grupos sociales, el uso de estrategias más o menos directas se relaciona con la necesidad de demostrar un poder social. De hecho, cuando un hablante procedente de un estatus superior se dirige a un inferior recurre con mayor frecuencia a la estrategia [+directo].

En su trabajo de 2008, Moreno González amplía la dimensión histórica de sus investigaciones previas y analiza la cortesía del español peninsular desde el español del Siglo de Oro hasta la época actual, con el objetivo de definir la distribución social de los usos y las formas lingüísticas de la cortesía verbal. En este caso, como corpus de estudio utiliza tanto obras dramáticas como novelas, a partir de las cuales se observan con claridad las diferencias de uso de la cortesía entre los diferentes grupos sociales (Moreno González, 2008, p. 414-415). La autora determina que, mientras los grupos sociales altos y bajos tienden al uso del aspecto 'volicional' de la cortesía, los grupos intermedios se rigen por 'usos sociales codificados'. Esta distribución del sistema de cortesía es esperable debido al poder significativo del dinero y a las pretensiones de ascenso social de la sociedad moderna española, frente a la sociedad estamental medieval que se regía por los patrones de honor y estatus.

Iglesias Recuero (2010) analiza los actos de habla directivos en dos comedias celestinescas del siglo XVI: la Segunda Celestina de Feliciano de Silva (1537) y la Comedia llamada Selvagia de Alonso Villegas Selvago (1554). Consciente de las restricciones y limitaciones que supone abordar la configuración de la cortesía desde un corpus histórico de textos literarios, la autora (2010, p. 374) defiende su uso siempre y cuando se reconozcan en ellos modelos estereotipados, no imitaciones, de las normas sociales del momento. Como modelo teórico, Iglesias Recuero sigue la propuesta de Spencer-Oatey (2008), en la cual la cortesía se concibe, de manera más amplia, como gestión de las relaciones interpersonales y considera la face como uno de los elementos que intervienen en ella. Para la clasificación de los actos de habla directivos se basa en el modelo de Blum-Kulka, House y Kasper (1989). Este estudio demuestra la variación histórica de la cortesía, por lo que la aplicación de las explicaciones y los principios actuales de la (des)cortesía no es válida para sus estudios diacrónicos. La principal conclusión a la que llega Iglesias Recuero (2010, p. 393) es que la ideología social determina los valores sociales de las formas lingüísticas, y, por tanto, su uso y su interpretación tanto en situaciones prototípicas como no prototípicas.

En un trabajo posterior, Iglesias Recuero (2016) realiza nuevas aportaciones al campo de la historia de los actos de habla. En esta ocasión, la autora estudia las formas de expresión de los actos ilocutivos de petición y orden en otro género 
discursivo, la ficción novelesca ${ }^{4}$. Iglesias Recuero elabora una clasificación de los actos de habla, dentro del 'espacio pragmático' (Jucker y Taavitsainen, 2000), basada en sus aspectos formales y en su grado de explicitud (Haverkate, 1994), parámetros a los que se adhieren las relaciones de poder y distancia, el coste (Leech, 2014) y el peso (Brown y Levinson, 1987). Los resultados principales de este estudio cuantitativo son los siguientes:

- una clara diferenciación de los actos de habla en función del contexto de uso. Se observa un predominio general de expresiones directas o explícitas, especialmente del imperativo, construcción no marcada y general, al menos en la representación novelesca de la interacción dialógica (Iglesias Recuero, 2016, p. 991), frente a la restricción contextual del resto de construcciones (enunciados realizativos, condicionales ilocutivas, construcciones mitigadores, preguntas sobre posibilidad o voluntad), que aparecen en situaciones de inferioridad del hablante o en las que el coste es elevado debido a las normas sociales del momento.

- la variedad de expresiones disponibles y la ausencia de formas convencionales indirectas habituales en el español actual, como las interrogaciones con poder o las cuasi-fórmulas relativas a la disposición del destinatario. Este inventario de expresiones coincide con los ya descubiertos en trabajos previos sobre la cortesía en el género dramático de los siglos XVI y XVII (Moreno González, 2003; Iglesias Recuero, 2010), lo que consolida el catálogo de formas disponibles para los hablantes de esta época.

Las publicaciones de King (2010b, 2012) son pioneras en trazar una historia de los actos de habla en el género epistolar, en concreto, se centra en los actos directivos de cartas familiares del siglo XVI y comienzos del siglo XVII. Como corpus de estudio, King (2010b) utiliza cien cartas familiares de emigrantes a Indias ${ }^{5}$, divididas según el sexo del emisor y el tipo de relación entre los interlocutores. Con el fin de esclarecer más los usos de la lengua de este período, el corpus de 2012 incluye dos fuentes primarias distintas: obras dramáticas (comedias y $\operatorname{pasos}^{6}$ ) y cartas familiares. El autor clasifica los actos directivos y sus estrategias de mitigación tomando como modelo la propuesta jerárquica de la fuerza ilocutiva de Koike (1992) y los analiza siguiendo las teorías sobre la cortesía verbal de Brown y Levinson (1987) y Blum-Kulka et al. (1989). Como novedad, King (2012, p. 140) introduce una comparación entre las modificaciones internas y externas de peticiones halladas en el corpus y los estudios sobre variedades habladas del español moderno. Al igual que ocurría en el estudio de Iglesias Recuero (2016) sobre la novela, los resultados revelan diferencias significativas entre los actos directivos observados en los corpus y los empleados en el español actual, tanto en su uso como

\footnotetext{
${ }^{4}$ El corpus objeto de análisis lo conforman seis Novelas ejemplares de Cervantes (La Gitanilla, El celoso extremeño, La ilustre fregona, La fuerza de la sangre, Las dos doncellas y La señora Cornelia), de las que se han seleccionado únicamente los enunciados que reproducen el discurso directo.

${ }^{5}$ Estas cartas han sido extraídas de una colección mayor de cartas privadas transcritas por Otte (1988). Para evaluar si el sexo del escritor de las cartas es determinante en el uso de los actos directivos, King (2010b, p. 256) seleccionó 44 cartas escritas por mujeres y 56 por hombres. Las cartas anónimas fueron excluidas, pues la relación interpersonal entre emisor-destinatario constituye uno de los ejes centrales de este trabajo.

${ }^{6}$ King (2012) estudia cuatro obras teatrales: tres comedias de Lope de Vega, La dama boba, El perro del Hortelano y El castigo sin venganza, y los Pasos de Lope de Rueda.
} 
en su estructura. Inequívocamente, las órdenes en modo imperativo ${ }^{7}$ son el tipo de acto directivo preferente en estas cartas; frente al resto de actos, que aparecen en contextos específicos en función de las relaciones de poder y solidaridad existentes: las peticiones aparecen con frecuencia alta en cartas escritas entre hermanos, y, por último, las sugerencias, actos infrecuentes en el corpus. King (2010b, p. 271) entiende esta variedad de estructuras directivas como una consecuencia del medio de comunicación empleado, el género epistolar, y no como una indicación de una tendencia sociocultural general. Sin embargo, en su siguiente trabajo, King (2012, p. 151) reconoce que las diferencias encontradas entre los documentos literarios y no literarios no son lo suficientemente importantes como para sugerir tendencias de uso, dado que solo un pequeño número de los elementos lingüísticos examinados ${ }^{8}$ depende directamente del género empleado.

Hay varias investigaciones recientes dirigidas a estudiar la correlación entre la tradición discursiva y la configuración de la cortesía. La tesis de Cruz Volio (2017) es una de ellas: estudia la representación de la (des)cortesía verbal en español medieval a través de un análisis de la formulación de distintos tipos de actos de habla, expresivos y discursivos, y de la modulación del entorno discursivo. La autora parte de una metodología cualitativa para estudiar su corpus, conformado por pasajes dialogados de varias obras de ficción medieval. A partir de las tendencias observadas en su trabajo, Cruz Volio (2017, p. 317) concluye que la cortesía verbal responde a expectativas de comportamiento relacionadas con el manejo del grado de imposición, retribución, deferencia e involucramiento. Además, corrobora que la representación de la imagen está asociada con los roles sociales e interaccionales que cumplen los personajes según el tipo de texto (Cruz Volio, 2017, p. 281), lo cual demuestra que la tipología textual literaria cumple un rol determinante en la expresión de la cortesía y que los textos de ficción son totalmente válidos para evaluar e interpretar la cortesía, pues no solo aportan un marco situacional, sino también un contexto histórico y sociocultural.

También se ha trabajado sobre la historia de una determinada estrategia pragmalingüística, en concreto la atenuación lingüística, como Leal Abad (2011) en debates medievales, Iglesias Recuero (2017) en textos tanto literarios como no literarios de mediados del siglo XVI y principios del siglo XVII o Gancedo Ruiz $(2018,2019)$ en varias obras del género dramático de los siglos XIX y XX ${ }^{9}$. El objetivo de Iglesias Recuero (2017) es estudiar la atenuación de las peticiones que aparecen en los textos epistolares y diálogos literarios de su corpus, conformado por dos clases diferentes de documentos, comprendidos entre mediados del siglo XVI y las dos primeras décadas del siglo XVII: unos pertenecen al ámbito literario (seis Novelas Ejemplares de Cervantes ${ }^{10}$ y la obra de teatro El Sagaz Estacio de Salas Barbadillo) y otros al no literario (cartas privadas de emigrantes a Indias y de Lope

\footnotetext{
${ }^{7}$ En los estudios del español actual, el uso del subjuntivo y del futuro sintético en las estructuras directivas constituye la tendencia mayoritaria (King, 2010b, p. 270).

${ }^{8}$ En pasos y comedias, King (2012, p. 151) constata un uso frecuente de los marcadores discursivos mira y oye, característicos de las variedades habladas del español.

${ }^{9}$ Comedias y dramas de J. Benavente (1896); Historia de una escalera y Las Meninas de A. Buero Vallejo (1949); Hoy es fiesta y El tragaluz. de Buero Vallejo (1956); El señor feudal de J. Dicenta (1896); Daniel de J. Dicenta (1907); El pan de cada día de M. Domingo (1926); El Grillo de C. Muñiz (1963); La camisa y El cuarto poder de L. Olmo (1961); La corbata de A. Paso (1963); La de San Quintín, Electra de B. Pérez Galdós (1894).

${ }^{10}$ Este conjunto de seis Novelas Ejemplares ha sido previamente estudiado por la propia autora en su trabajo de 2016.
} 
de Vega al Duque de Sessa). Los datos extraídos coinciden con los estudios realizados sobre el español áureo (Iglesias Recuero 2016; Moreno González 2003; King 2010b): más del $80 \%$ de las peticiones se realizan con la construcción más directa, la imperativa, y la formulación indirecta, caracterizada por el uso de distintos atenuadores, apenas alcanza el 15\% (Iglesias Recuero, 2017, p. 298). Tan solo un $25 \%$ de las peticiones resultan atenuadas, lo que supone una notable diferencia respecto al español actual, donde se suelen atenuar más del 50\% de los actos de habla. Este estudio revela la influencia en la estrategia pragmática de atenuación de varios parámetros contextuales como las relaciones sociales e interpersonales y su misma concepción, el género, el estatus social o el coste. Así, el menor porcentaje de atenuación se halla en las cartas dirigidas por varones a sus esposas (caracterizadas por un alto grado de familiaridad, afecto y poder masculino); en el otro extremo, con el mayor grado de atenuación, se encontrarían las cartas de Lope de Vega, fuertemente condicionadas por la distancia social (Iglesias Recuero, 2017, p. 311).

\section{La historia de la lengua y sus fuentes documentales de estudio}

Uno de los aspectos que ha propiciado el asentamiento de la pragmática histórica como disciplina ha sido el cambio de actitud hacia las fuentes documentales de estudio, al aportar una base metodológica. Como se ha repetido en numerosas ocasiones, trabajar en diacronía de la lengua presenta varios problemas intrínsecos en relación con los documentos de análisis, pues estos siempre son textos escritos que han sobrevivido mayormente por azar. Problema que se agrava al tratar temas relativos a la pragmática o al discurso oral, disciplinas que han mostrado una clara preferencia por analizar fuentes orales. Romaine (1982), una de las pioneras en enfocar diacrónicamente la sociolingüística, señala que, "pese a las dificultades metodológicas que concurren en el análisis de periodos antiguos, es posible reconstruir los estadios de lengua pasados en su contexto social a través, principalmente, de la diferenciación estilística".

En los últimos años, se han producido cambios profundos en la tipología de las bases de datos estudiadas desde la pragmática histórica. Así, se ha pasado de considerar válidos exclusivamente los datos obtenidos a través de conversaciones auténticas ${ }^{11}$ a analizar datos extraídos de textos escritos e incluso literarios (Jucker, 2008). Este miramiento hacia las fuentes escritas como objeto fiable de estudio, considerándolas un testimonio aproximado a la oralidad, ha sido la base para las investigaciones llevadas a cabo en diversas lenguas en esta nueva disciplina histórica.

De notable importancia en este cambio de perspectiva ha sido la influencia del modelo presentado por Koch y Oesterreicher (1985/1990), en el cual la dicotomía entre lo escrito y lo hablado no se manifiesta como una oposición irreconciliable, sino que se relaciona en un continuum, limitado por dos extremos, denominados inmediatez comunicativa y distancia comunicativa ${ }^{12}$.

\footnotetext{
${ }^{11}$ Como entrevistas o interacciones simuladas.

12 Este dominio conceptual depende de parámetros que se refieren a determinadas condiciones de comunicación, entre las que destacan: privacidad de la comunicación, conocimiento mutuo de los interlocutores y saber compartido, participación emocional, cooperación, espontaneidad o integración del discurso en el contexto situativo y accional.
} 
El trabajo con fuentes escritas constituye, según Osterreicher (2004, p. 731), un reto general para el estudio diacrónico de cualquier lengua, pero no lo imposibilita. De hecho, en los documentos escritos también se encuentran evidencias $^{13}$ más o menos directas de las formas y variantes lingüísticas características de lo hablado. Si bien es cierto que no todos los documentos escritos antiguos presentan las mismas características, existen ciertos tipos de textos (Oesterreicher, 2004, p. 747) en los que se puede presumir un acercamiento a la lengua vernácula de tiempos pretéritos, como las cartas, los diarios o los documentos autobiográficos.

Por otra parte, los avances en lingüística de corpus y procesamiento de datos (Taavitsainen y Jucker, 2010, p. 17; Faya Cerqueiro y Vila Carneiro 2014, p. 55; Kabatek, 2016, p. 2) han contribuido a despertar el interés de los investigadores en la proyección de la lingüística histórica hacia aspectos pragmáticos, incluyendo también el análisis de la (des)cortesía. El desarrollo de estas metodologías, con su consiguiente aumento de corpus de lengua hablada y escrita, ha permitido tomar en consideración las condiciones contextuales de los documentos de estudio, favoreciendo la eclosión de los estudios (socio)pragmáticos históricos. Así, la digitalización de estas bases de datos posibilita no solo recoger información de los conjuntos de obras volcadas con tratamiento informático, sino que, gracias a su etiquetado, también facilita la realización de búsquedas y la obtención de concordancias. A través de esta ampliación de los datos reales disponibles, la lingüística de corpus ha dotado de un mayor grado de fiabilidad a los estudios realizados con ellos al posibilitar la elaboración de réplicas e incluso permitir el descubrimiento de nuevos resultados (Conde Silvestre, 2007, p. 47).

El primer corpus histórico, el Helsinki Corpus of English Texts (siglos VIII XVIII), fue recopilado en los años ochenta y publicado en 1991 por un grupo de lingüistas de la Universidad de Helsinki, bajo la dirección de Rissanen y Ihalainen. Este corpus ha sido etiquetado en correlación a diversos factores, como el dialecto en que se escribe cada texto, el género discursivo al que pertenece o información específica de sus autores, siempre que esta sea conocida (sexo, edad, estatus social y relación con los receptores). Desde ese momento, los corpus se convirtieron en una herramienta fundamental para la lingüística histórica, poniendo a su disposición material digitalizado de libre acceso, de distintas épocas y en diferentes idiomas. Además, en los últimos años han proliferado otros corpus con un carácter más especializado, llamados de tercera generación (Koester, 2010), de cuyos avances en el desarrollo de herramientas computarizadas se ha beneficiado notoriamente la pragmática histórica.

En el ámbito hispánico, ha resultado esencial la labor de dos proyectos: red $\underline{\text { CHARTA }}^{14}$ y $\underline{\text { CORDIAM }}^{15}$. El primero no solo ha establecido una metodología común para la edición de textos y la creación de corpus documentales, sino que ha puesto a disposición de los investigadores un amplio corpus de documentos, entre los siglos XII y XIX, abarcando la variedad geográfica del español. El segundo, dada

\footnotetext{
${ }^{13} \mathrm{Al}$ no lograr captar nunca directamente la manifestación del lenguaje hablado auténtico en textos, Oesterreicher (1996, p. 323) prefiere hablar de evidencias de lo hablado en lo escrito, en lugar de usar el término oralidad.

${ }^{14}$ En el siguiente apartado se amplía la información relativa a este proyecto.

${ }^{15}$ Corpus electrónico, de libre acceso, dirigido por Concepción Company y Virginia Bertolloti y creado en 2015. A su vez CORDIAM reúne tres conjuntos documentales: CORDIAM-Documentos, CORDIAM-Literatura y CORDIAM-Prensa.
} 
su especificidad americana y su amplitud cronológica (entre los siglos XVI y XIX), constituye una sólida base para investigar la dialectología histórica de la lengua española en América.

\section{Fuentes documentales de estudio de la (des)cortesía verbal histórica}

La propia disciplina de la pragmática se enfrenta a numerosos problemas para identificar algunos rasgos pragmáticos en la lengua. A estos problemas, la pragmática histórica añade otros relativos a las fuentes de estudio, al no ser posible la elaboración de cuestionarios o encuestas en análisis de estadios anteriores de la lengua (Blum-Kulka et al., 1989; Culpeper y Archer, 2008; Taavitsainen y Jucker, 2008). En comparación con la diversidad, cantidad y autenticidad de los datos disponibles para los estudios sincrónicos, la información a disposición de las investigaciones históricas es fragmentaria ${ }^{16}$, escasa y difícilmente vinculable con la producción real de los hablantes ${ }^{17}$ (Conde Silvestre, 2007, p. 35). Además, el investigador en pragmática histórica debe reconstruir el contexto social a partir de datos históricos ${ }^{18}$, pues no posee un conocimiento de primera mano de factores como, por ejemplo, las actitudes o la estratificación social de una comunidad, datos que sí están a disposición del investigador en pragmática sincrónica.

Desde esta perspectiva, una reconstrucción contextual válida y completa debe atender a los siguientes factores (Moreno Fernández, 1998, pp. 98-103):

1) Factores personales, que incluyen: i. el hablante y el control que este ejerce sobre su producción lingüística, además de las restricciones históricogeográficas y sociolingüísticas a las que está sometido; ii. los interlocutores, la cantidad de ellos que participan y la atención que prestan al mensaje, y iii. el tipo de relación que se establece entre ellos (formal, familiar, casual, íntima, etc.), manifestada en el ejercicio de poder y/o solidaridad.

2) Factores no personales: i. elementos discursivos como el tema, el tipo de comunicación y el género discursivo; y ii. elementos contextuales, como el lugar, el momento en que ocurre la interacción comunicativa (adecuado o no) y el tipo de actividad (pública o privada) que se desarrolla.

Taavitsainen y Jucker (2010, pp. 15-21) exponen las principales dificultades surgidas al investigar épocas anteriores desde la pragmática. Entre ellas destacan la identificación de patrones de cambio lingüístico en pragmática histórica, la fiabilidad a la hora de reconocer la correspondencia entre forma y función, la categorización de rasgos pragmáticos concretos, la adscripción de elementos a una u otra categoría y la contextualización a niveles macro y microlingüísticos.

\footnotetext{
${ }^{16} \mathrm{Su}$ carácter fragmentario se debe a dos motivos: la escasa variación estilística y social. El primero está relacionado con la falta de representación de todos los estilos o variedades del pasado y el segundo, a la carencia de muestras pertenecientes a todos los niveles sociales de las comunidades históricas. En numerosos casos, el investigador en lingüística histórica no suele disponer de información sobre los estratos más bajos de la sociedad, frente a la fácil disposición por parte del investigador en sincronía de datos procedentes de todo el espectro de población.

${ }^{17} \mathrm{El}$ grado de autenticidad de los textos pasados ha planteado numerosas dudas por la presencia de escribanos, los fenómenos de autocorrección o la mezcla de dialectos (Blas Arroyo, 2019, p. 30).

${ }^{18}$ La historia social, disciplina que trata la conformación de distintos grupos sociales en el pasado, incluyendo su estructura, sus relaciones y sus conflictos entre ellos (Burke, [1987] 1980 y 1992), se ha convertido en una herramienta auxiliar de la lingüística histórica, al ofrecer al investigador la información necesaria para la reconstrucción del contexto.
} 
Pese al evidente desarrollo y avance metodológico en los estudios sobre (des)cortesía histórica en español, los trabajos con fuentes no literarias permanecen a la sombra del auge de las investigaciones con corpus literarios ${ }^{19}$, si bien es cierto que progresivamente va incrementándose el número de investigaciones centradas en textos no literarios.

Numerosos autores (Brown and Gilman 1989; Culpeper y Kytö 1999; Salmon 1987; Taavitsainen 1995; Gancedo Ruiz, 2016) inciden en el valor de las obras dramáticas como muestras de lenguaje auténtico, dado que generalmente se componen con el propósito expreso de ser realizadas frente a un público contemporáneo, el cual debe reconocer como comunes a su tiempo el lenguaje y la sociedad representados. Jucker (1994, p. 535) va más allá y afirma que el teatro, al ser un texto puramente dialógico sin intervenciones del narrador, es un género totalmente apropiado para analizar las conductas de cortesía en otras épocas.

Sin embargo, no son pocos los investigadores que se han alzado en contra de considerar la literatura como muestra válida para el análisis de la lengua por su estatus de ficción y por sus pretensiones de estilo, llegando incluso a cuestionar la veracidad con que estarían representadas las interacciones reales coetáneas (Iglesias Recuero, 2010, p. 270; Gancedo Ruiz, 2016, p. 165). No obstante, la ficcionalidad e intención estilística de las obras literarias no son un impedimento para realizar un análisis pragmático, sino que meramente son un parámetro, a seguir por el analista, para determinar qué obras conforman un corpus de estudio pragmático diacrónico válido. Además, siguiendo a Gancedo Ruiz (2016, p. 166), hay obras que intentan reflejar el habla real de su época con mayor rigor, por lo que "es necesario que el texto que se tome como objeto de análisis sea verosímil en tanto que el conjunto de presupuestos sociolingüísticos e ideológicos se correspondan con el momento histórico en que se plantean". Iglesias Recuero (2010, p. 271) recoge cuatro propiedades de los corpus literarios que los legitiman para la investigación histórica: su verosimilitud, su naturaleza discursiva, la variedad de situaciones y de valores sociales que presentan y su relación dialéctica con las ideologías sociales.

Este trabajo no pretende cuestionar el empleo de textos literarios en estudios pragmáticos históricos pues, como se ha demostrado en numerosas investigaciones previas, su manejo es totalmente válido, efectivo y relevante; sino que persigue ampliar el estudio de la (des)cortesía histórica tomando como fuente documental el género epistolar. En el ámbito hispánico, son varios los investigadores que han llamado la atención sobre el escaso interés que han despertado los textos no literarios en el ámbito de la diacronía, entre ellos Narbona (1989), Cano Aguilar (1996), Rivarola (2000), Fernández Alcaide (2009) o Ramírez Luengo (2016). El estudio con fuentes documentales archivísticas (cartas, billetes, documentos notariales, de tipo administrativo, tratados médicos, etc.) permite complementar y completar los datos extraídos previamente de investigaciones realizadas sobre datos literarios, en tanto que podrá demostrar si lo que aparece en la literatura es algo general en el habla o una particularidad de esa tradición textual y aportará información sobre fenómenos lingüísticos que, por diversas cuestiones, no pueden darse en la tipología textual literaria (Ramírez Luengo; 2016, p. 90).

\footnotetext{
${ }^{19}$ La pragmática histórica no es la única disciplina diacrónica que recurre al empleo de la literatura para sus análisis. Los estudios pioneros en historia de la lengua española son algunos ejemplos de investigaciones con material de tipo literario, destacando los excelentes trabajos históricos del Rufino José Cuervo (1895, 1988, 1994), de Ramón Menéndez Pidal (1954) sobre el Mio Cid o la fundamental Historia de la lengua española de Rafael Lapesa (1980).
} 
De esta forma, la tipología epistolar ofrece un interés histórico indudable. Esto explica que se haya utilizado en múltiples ocasiones para reconstruir diatópica y diacrónicamente el español (Bentivoglio, 2003; Bertolotti, Coll y Polakof, 2012; Calderón Campos, 2001, 2006, 2010, 2012; Company, 1993; Fernández Lávaque, 2005; Fernández Alcaide, 2009; Fontanella de Weinberg, 1989; Franco Figueroa, 2011; García Godoy, 2002, 2010, 2012a, 2012b; Gómez Seibane, 2004; Isasi Martínez, 2012; Lope Blanch, 1985; Macías Domínguez, 2016; Navarro Gala, 2002; Ramírez Luengo, 2006, 2010, 2013; Tabernero Sala, 2020). Fundamental en su consolidación como documento de estudio histórico ha sido también la labor de la "red CHARTA", surgida en 2005 y destinada a la publicación en red de un macrocorpus de textos y documentos antiguos de España e Hispanoamérica, desde el siglo XII hasta el XIX. Este proyecto global de edición de textos archivísticos panhispánicos pretende integrar una sólida fundamentación filológica y los desarrollos informáticos, proporcionando así a los investigadores de historia de la lengua española unos textos digitales fiables y fácilmente comprobables.

A pesar de la existencia de trabajos sobre la historia y tipología del género epistolar en lengua inglesa (Corpus de correspondencia inglesa temprana, 1410$1681^{20}$ ) y española ${ }^{21}$, sobre la manifestación de la (des)cortesía en este género los trabajos son aún escasos en español, realizados sobre corpus muy limitados y restringidos a los siglos XVI y XVII. No obstante, recientemente los siglos XVIII y XIX han ido cobrando interés, como reflejan los resultados de varias investigaciones (Martínez Pasamar, 2019; Martínez Pasamar y Tabernero Sala 2019; Bello Hernández, 2019; Albitre Lamata, 2019; Tabernero Sala, 2020).

En este punto, resultan evidentes las infinitas posibilidades de los corpus, sean textuales $\mathrm{u}$ orales, literarios o no, como herramienta para los estudios diacrónicos de las lenguas. Los datos de los corpus no nos ofrecen la historia de la lengua como tal, sino que nos permiten tener una visión indirecta, por ello se deben recontextualizar en función de los factores de su producción (Oesterreicher, 2004). Aunque todo texto está ineludiblemente determinado por el contexto sociocultural en el que surge, no existe una fuente de información de primer orden para los trabajos diacrónicos, pues será tarea del investigador diseñar y construir exhaustivamente un corpus de estudio con materiales útiles y válidos a la hora de analizar e interpretar un aspecto concreto de la evolución diacrónica de una lengua. Consecuentemente, en estudios más minuciosos, como los centrados en la evolución de la (des)cortesía en el género epistolar, surge la necesidad de elaborar un corpus amplio, suficientemente representativo y fiable, diseñado con rigor filológico específicamente para abordar ese aspecto. Esta perspectiva metodológica es una de las claves, y no un simple instrumento auxiliar, para poder resolver las preguntas que nos plantea la evolución de los actos de habla y las estrategias de atenuación e intensificación en nuestra lengua.

A la hora de componer un corpus diacrónico nos encontramos con una paradoja (Enrique-Arias, 2012, p. 96): "por un lado deben ser heterogéneos, en tanto

\footnotetext{
${ }^{20}$ Proyecto dirigido por un grupo de investigación de la Universidad de Helsinki. En él se aplica una metodología sociolingüística y pragmática al análisis de la correspondencia, desde el s. XVI en adelante, por lo que se potencia la relación de rasgos gramaticales del discurso epistolar con factores de tipo sociológico como el nivel social, educativo y cultural, la edad y el sexo de los participantes.

${ }^{21}$ Aunque la tradición epistolar ha sido ampliamente estudiada desde la retórica, apenas ha sido atendida desde un punto de vista más estrictamente lingüístico, como denuncian Cano Aguilar (1995) o Fernández Alcaide (2009).
} 
que tienen que incluir textos de diferentes autores, épocas, géneros, registros y dialectos para ser lo más representativos posibles, y, a la vez, deben ser homogéneos, pues los diferentes cortes sincrónicos representados en el corpus tienen que ser comparables entre sí". Solo a partir de una correcta identificación y etiquetado de esos factores de heterogeneidad se podrá analizar un fenómeno concreto en la historia de la lengua.

Jacobs y Jucker (1995, p. 8) afirman que las cartas, en particular las cartas privadas, son una fuente de estudio fundamental para la pragmática diacrónica $y$, más en particular, para la (des)cortesía histórica. Existen cuatro rasgos característicos de esta tipología textual que avalan su uso en este tipo de estudios:

i. presenta con mayor frecuencia que otras tipologías textuales rasgos característicos del lenguaje coloquial y hablado, al situarse más próxima al polo de la inmediatez comunicativa (Koch y Oesterreicher, 1990). Algunas cartas privadas, de temática informal, llegan a representar el lenguaje espontáneo y menos planificado característico de una tipología coloquial. Según Koch y Oesterreicher (2001, p. 613), las cartas más apropiadas para llevar a cabo este estudios históricos de cortesía se situarían en el campo C del esquema 1, al emplear el medio el gráfico y presentar, desde el punto de vista concepcional, un discurso oral.

Esquema 1. Dominio conceptual (koch y Oesterreicher, 2001).

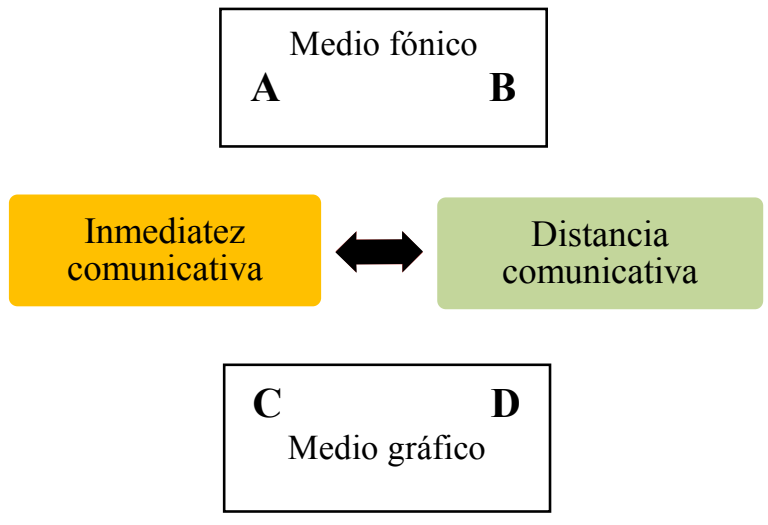

ii. contiene numerosas secuencias de interacción comunicativa, con su correspondiente carga afectiva, tales como actos expresivos (saludos, despedidas), actos directivos, marcadores de (des)cortesía o actos comisivos, que dependen estrechamente de las relaciones sociales del momento y que permite observar la adecuación de la noción de cortesía a los preceptos socioculturales de cada época. Asimismo, posibilita la clasificación de los elementos que componen los enunciados siguiendo la teoría de los actos de habla de Blum-Kulka y House $(1989)^{22}$.

iii. su originalidad y su precisa ubicación espacio-temporal. El momento histórico condiciona la lengua y proporciona al autor unas herramientas expresivas y unos temas determinados, por lo que se presuponen ciertos conocimientos compartidos a la hora de redactar una carta: elementos de la psicología humana, sistema de valores de un medio o una época, dominio

\footnotetext{
${ }^{22}$ Este modelo es una de las propuestas más complejas y adecuadas para analizar los actos de habla, pues se basa en la distinción entre acto principal y actos de apoyo.
} 
del lenguaje coetáneo, especificidad histórica del mundo, etc. (Gancedo Ruiz, 2016, p. 167). En general, estos materiales son originales ${ }^{23} \mathrm{y}$ presentan la fecha de redacción y el lugar donde se escriben, lo que les confiere una especial relevancia para describir un estado de lengua en una diatopía y una diacronía concretas. Precisamente, esta concreta ubicación espacio-temporal permite reconstruir parcialmente el contexto $^{24}$ (destacando el papel de las relaciones entre los interlocutores) y abordar así el estudio de los enunciados (des)corteses, constituidos a su vez por varios actos de habla interdependientes, ya que solamente tomándolos en conjunto se podrán interpretar sus efectos.

iv. su realismo y su finalidad interaccional y utilitaria. A diferencia de los textos literarios, esta clase de documentación no plantea ningún problema especial de representatividad, salvando las convenciones asociadas a su tradición discursiva, como la presencia de fórmulas de cierre y despedida propias. En las cartas privadas, se incrementa el grado interaccional respecto a otro tipo de misivas, como las cartas de otorgamiento o de poder, pues el emisor se implica en mayor medida e implica también más al destinatario (Carrera de la Red, 2013, p. 18), lo que facilita el estudio de la (des)cortesía.

A pesar de estas características del género epistolar, debemos ser conscientes de la dificultad metodológica general que plantean las fuentes escritas, ya sean literarias o no, pues en ellas nunca encontraremos lo hablado en estado auténtico, tan solo podremos presumir un acercamiento a la lengua utilizada en épocas pretéritas, es decir, una representatividad relativa. Con respecto a estas limitaciones, Taavitsainen y Jucker (2002:8) reconocen que los textos no dan acceso directo al lenguaje hablado de esa época, sino que representan una muestra de reglas sociolingüísticas o principios pragmáticos asociados a una comunidad de habla determinada de un tiempo concreto ${ }^{25}$.

Los corpus históricos conformados por cartas, más específicamente cartas privadas y familiares, han sido considerados, en numerosas ocasiones ${ }^{26}$ (Elizaincín y Groppi, 1991; Bentivoglio 2003; Fitzmaurice 2002; Fontanella de Weinberg 1994; Ramírez Luengo, 2016; Blas Arroyo, 2019), como los más útiles al llevar a cabo una reconstrucción lingüística histórica y manifestar en sí estrategias orales o coloquiales, susceptibles de aparecer también en la oralidad de estadios anteriores de la lengua. Las fuentes de carácter personal, como este tipo de correspondencia, arrojan información que revela las motivaciones individuales y sociales del

\footnotetext{
${ }^{23}$ De su finalidad puramente utilitaria se deriva su carácter de texto único, por lo que no es necesario dar a conocer a un gran público y no se reproduce en reiteradas ocasiones a lo largo del tiempo como sí ocurre con ciertos textos literarios (Palander-Colin y Nevala, 2005; Blas Arroyo, 2019).

${ }^{24}$ En ocasiones, esta reconstrucción parcial también es posible a partir del propio contenido de la carta.

${ }^{25}$ A pesar de no reflejar de manera fidedigna la lengua hablada del pasado, los textos escritos sí dan acceso a la lengua que se usaba en un momento cronológico determinado, pues esta siempre se emplea siguiendo unas normas determinadas por factores como los de la propia tradición discursiva, la relación existente entre los interlocutores o las particularidades históricas de la época.

${ }^{26}$ Las investigaciones emprendidas desde la sociolingüística histórica (Blas Arroyo, 2005 y 2019) consideran tarea imprescindible la compilación de un corpus de obras lo más próximas a la oralidad posible, por eso recurren preferentemente a textos como las cartas privadas, cercanos al polo de la inmediatez comunicativa (Koch y Oesterreicher, 1985)
} 
momento y, asimismo, permiten recuperar otro tipo de pruebas de la historia, diferentes a las que proporcionan los documentos archivísticos oficiales.

Cabe precisar que, debido a la complejidad estructural de la cortesía, en su estudio no se debe buscar un reflejo fiel de la oralidad de periodos remotos ${ }^{27}$. El objetivo de estos estudios debe ser comprender la configuración de la (des)cortesía en un género discursivo concreto (en este caso el epistolar) y en un determinado corte sincrónico, tras elaborar un correcto etiquetado de las construcciones del corpus a partir de variables lingüísticas, sociopragmáticas y discursivas. Este etiquetado debe incluir las siguientes características de cada carta, en la medida en que sea posible: nombre y tipo de la remitente, destinatario, relación entre ambos, objetivo de la carta, principales argumentos utilizados en las peticiones (coste y beneficio), asunto general de la misiva, si es autógrafa, fecha y lugar de escritura, tipología de los actos de habla y su disposición textual.

Cada género discursivo se presupone que responde a las presiones de la situación en la que se produce, de tal manera que se acomoda a los objetivos de la comunicación, dando lugar a diferencias entre géneros. Las cartas se integran en el género epistolar, por lo que también sufren la proyección de normas, convenciones y rasgos modélicos del conjunto, de tal forma que los actos de habla presentes en ellas se verán afectados por el discurso, en algunas ocasiones formulario y rígido, característico de la tipología textual epistolar (Frago, 2002, p. 118; Ramírez Luengo, 2016, p. 2).

\section{Conclusiones: tareas para el futuro}

A pesar de que la pragmática histórica es una rama de la lingüística relativamente actual, en los últimos años ha habido un gran avance en la conceptualización de la cortesía desde su historicidad. Se entiende que la misma noción de cortesía ha ido evolucionando y modificándose históricamente para adaptarse a las actividades sociales de cada momento. En este sentido, se insiste en que las expresiones de cortesía solamente se pueden explicar por determinadas condiciones sociales y tipos de comportamiento que cambian a través del tiempo.

Son varias las características intrínsecas de la tipología textual epistolar que avalan su uso en estudios pragmático-históricos: su finalidad interaccional, su originalidad, su precisa ubicación espacio-temporal, su alta frecuencia de rasgos característicos del lenguaje coloquial y hablado, especialmente en la carta privada, y la aparición de numerosas secuencias de interacción comunicativa, dependientes de las relaciones sociales del momento. En definitiva, pese a sus restricciones derivadas de la rigidez formal y el automatismo lingüístico de cualquier texto escrito, se hace del todo evidente la importancia que posee la documentación epistolar para el estudio de la historia de la lengua y, más específicamente, de la pragmática histórica. Y es que, como señala García Mouton (1999a, p. 264), “los textos literarios pueden imitar la realidad; las cartas, aun sometidas a todo tipo de molde, forman parte de ella".

Completar la laguna textual y cronológica de los estudios sobre la (des)cortesía hispánica, que incluye el género epistolar y va desde el siglo XVII hasta el XIX, supone una tarea futura para los filólogos. El primer paso para llevarla a cabo es contar con la documentación epistolar necesaria y el siguiente realizar una

${ }^{27}$ Aunque sí se debe perseguir una mayor aproximación al habla vernácula, objetivo que dependerá de las condiciones de los escribientes. 
confección específica y adecuada del corpus de estudio. Aunque apenas han sido empleados en estudios cortesiológicos, son incalculables los documentos epistolares, tanto peninsulares como americanos, a disposición de los investigadores que atestiguan el español de ese corte temporal. Afortunadamente, gran cantidad de estos materiales están ya digitalizados, destacando epistolarios privados anónimos ${ }^{28}$ $\mathrm{y}$ de personalidades ${ }^{29}$, y se han desarrollado varias investigaciones recientes en ese corte temporal (Albitre Lamata, 2019), Bello Hernández, 2019; Martínez Pasamar, 2019; Tabernero Sala, 2019), lo que posibilita la continuación de esta tipología de estudios. No obstante, los archivos históricos todavía conservan correspondencia privada sin catalogar ni estudiar, por lo que también sería conveniente comenzar a sumergirse en estos materiales para completar los conocimientos sobre la conformación histórica de la cortesía en español.

No es tarea fácil ni sencilla emprender estudios pragmáticos sobre el pasado, pero es pertinente y posible gracias a la ayuda tanto de la lingüística de corpus, que pone a disposición de los investigadores una metodología y unos materiales afines, como de nuestros compañeros. Articular una visión más completa y coherente de nuestro pasado es una tarea colectiva, no individual. Solo trabajando de forma conjunta y colaborativa, conseguiremos conocer, de una forma más ajustada a la realidad, cómo se ha ido configurando la (des)cortesía a lo largo del tiempo.

\section{Referencias}

1. Albitre Lamata, P. (2019): Análisis de los mecanismos de cortesía en cartas españolas del S. XVI. Revista de Filología y Lingüística de la Universidad de Costa Rica, 45(2), pp. 27-66. DOI: https://doi.org/10.15517/rfl.v45i2.39113

2. Alonso Raya, R. (1998): Competencia comunicativa y cortesía. Cuestiones metodológicas. En ASELE (Ed.), El Español como lengua extranjera: aspectos generales. Reedición de las Actas de las Primeras Jornadas Pedagógicas y del Primer Congreso de ASELE (pp. 43-52). Málaga: Asociación para la Enseñanza del Español como Lengua Extranjera.

3. Alonso-Cortés, M. D., Garrido, M. C. y Villayandre, M. (2001): Recursos pragmáticos para favorecer la eficacia argumentativa de los estudiantes de E/LE. En ASELE (Ed.), ¿Qué español enseñar?: norma y variación lingüisticas en la enseñanza del español a extranjeros. Actas del XI Congreso Internacional ASELE (pp. 733742). Zaragoza: Universidad de Zaragoza.

4. Bax, M. y D.Z. Kádár (Eds.) (2012): Understading Historical (Im)politeness, Ámsterdam/Filadelfia: John Benjamins. DOI: https://doi.org/10.1075/bct.41

5. Bello Hernández, I. (2019): La cortesía en Canarias a finales del siglo XVIII y principios del XIX: saludos, despedidas y formas de

\footnotetext{
${ }^{28}$ Como, por ejemplo, las cartas privadas de la Red CHARTA (peninsulares y americanas), del CORDIAM (americanas) o del corpus de Cartas de Ultramar a España (1823), conformado por 65 cartas escritas desde Ultramar (sobre todo desde Puerto Rico) a la Península Ibérica. Cabe destacar que ya se están obteniendo resultados de estos epistolarios.

${ }^{29}$ Los epistolarios privados de Sor María Jesús de Ágreda, Felipe IV, Lope de Vega, Góngora, Quevedo, Sor María Jesús de Ágreda, Felipe IV, Cadalso, Jovellanos, Moratín, Samaniego, Pérez Galdós, Pardo Bazán, Rosalía de Castro, Alas Clarín, Emilio Castelar, Delmira Agustini, Andrés Lamas, José Gervasio Argigas, Fructuoso Rivera o Bernardina Fragoso, entre otros, ya se encuentran digitalizados, lo que facilitaría la conformación de un corpus para el estudio de la cortesía histórica.
} 
tratamiento en un corpus de cartas. (Trabajo final de máster). Universidad Complutense de Madrid.

6. Bentivoglio, P. (2003): Spanish forms of adddress in the XVI century. A pragmatic analysis of vos and vuestra merced. En Taavitsainen, I. y Jucker, A. H. (Eds.), Diachronic Perspectives on Adress Term Systems. Ámsterdam/Filadelfia: John Benjamins (Pragmatics Beyond New Series, 107).

7. Bertolotti, V., Coll, M. y Polakof, A. C. (2012): Documentos para la historia del español en el Uruguay, 2. Cartas personales y documentos oficiales y privados del siglo XIX. Montevideo: Universidad de la República.

8. Blas Arroyo, J. L. (2005): Sociolingüística del español. Desarrollos y perspectivas en el estudio de la lengua española en contexto social. Madrid: Cátedra.

9. Blas Arroyo, J. L. (Dir.), Porcar Miralles, M., Velando Casanova, M. y Vellón Lahoz, J. (2019): Sociolingüistica histórica del español. Tras las huellas de la variación y el cambio lingüístico a través de textos de inmediatez comunicativa. Madrid/Fráncfort del Meno: Iberoamericana/Vervuert.

10. Blum-Kulka, S., House, J. y Kasper, G. (Eds.) (1989a): Cross-Cultural Pragmatics: Requests and Apologies. Norwood: Ablex

11. Bolívar, A. (2010): Ideologías y variedades de descortesía. En Bernal, M y Hernández Flores, N. (Eds.), Estudios sobre lengua, discurso y sociedad. Homenaje a Diana Bravo (pp. 31-56). Estocolmo: Universidad de Estocolmo.

12. Bravo García, E. (2004): Tratamientos y cortesía en la correspondencia familiar indiana del siglo XVIII. Archivo de Filología Aragonesa, 59-60(1), pp. 249-264.

13. Brinton, L. J. (2001): Historical discourse analysis. En Schiffrin, D., Tannen, D. y Hamilton, H. E. (Eds.), The handbook of Discourse Analysis (pp. 138-160). Malden, Massachusetts/Oxford: Blackwell.

14. Briz, A. (2004): Cortesía verbal codificada y cortesía verbal interpretada en la conversación. En Bravo, D. y Briz, A. (Eds.), Pragmática sociocultural: estudios sobre el discurso de cortesía en español (pp. 67-93). Barcelona: Ariel.

15. Brown, P. y S. Levinson ([1978] 1987): Politeness. Some Universals in Language Usage. Cambridge, Cambridge University Press. DOI: https://doi.org/10.1017/CBO9780511813085

16. Brown, R. y Gilman, A. (1960): The Pronouns of Power and Solidarity. En Sebeok, T. A. (Ed.), Style in Language (pp. 253-276.). Cambridge, Mass: MIT Press.Caffi/Janney.

17. Burke, P. (1980): Sociology and History. Londres: Allen and Unwin. Traducción al español: Sociología e Historia, Madrdid, Alianza, 1987.

18. Burke, P. (1992): History and Social Theory. Cambridge: Polity Press.

19. Bustos Gisbert, E. (2007): La expresión de la cortesía en Bernal Díaz del Castillo. En Puigvert Ocal, A. y Delgado Cobos, I (Coords.), Ex admiratione et amicitia. Homenaje a Ramón Santiago (pp. 159-178). Madrid: Ediciones del Orto.

20. Bustos Gisbert, E. (2016): Tratamientos nominales: hermana en el español áureo, En López, Serena, A., Narbona, A. y Rey Quesada, S. 
del (Eds.), El español a través del tiempo. Estudios ofrecidos a Rafael Cano Aguilar (Vol. 2, pp. 741-753). Sevilla: Servicio de Publicaciones de la Universidad de Sevilla.

21. Bustos Gisbert, E. e Iglesias Recuero, S. (2003): Relaciones familiares y formas de tratamiento en la novela realista del siglo XIX. En Girón Alconchel, J. L., Iglesias Recuerdo, S., Herrero Ruiz de Loizaga, F. J. y Narbona, A. (Coords.), Estudios ofrecidos al profesor José Jesús de Bustos Tovar (Vol. 1, pp. 277-296), Madrid: Editorial Complutense.

22. Bustos Tovar, J. J. (2000): Texto, discurso e historia de la lengua. Revista de Investigación Lingüística, 3(2), pp. 67-94.

23. Calderón Campos, M. (2001): Fórmulas de tratamiento sociales en obras literarias andaluzas de la segunda mitad del siglo XIV. Cuadernos del Sur. Letras, 31, pp. 7-35.

24. Calderón Campos, M. (2003): Fórmulas de tratamiento en las cartas del conde de Tendilla (1504-1506). Tonos-Digital. Revista electrónica de estudios filológicos, 5.

25. Calderón Campos, M. (2006): El desgaste pronominal y verbal de vos en la primera mitad del siglo XVI. En Bustos Tovar, J. J. de y Girón Alconchel, J. L. (Eds.), Actas del VI Congreso Internacional de Historia de la Lengua Española (Vol. 1, pp. 557-568). Madrid, Arco Libros.

26. Calderón Campos, M. (2010): Los elementos nominales en el sistema de tratamiento del español de Andalucía durante la Restauración (1875-1931), En Hummel, M., Kluge, B. y Vázquez Laslop, M. E., Formas y fórmulas de tratamiento en el mundo hispánico (pp. 551-570). México, D. F./Graz: El Colegio de México, Centro de Estudios Lingüísticos y Literarios/Karl Franzens Universität.

27. Calderón, M. (2012): Particularidades léxicas de las cartas de dote de los moriscos granadinos (1509-1513). Cuadernos del Instituto de Historia de la Lengua, 7, pp. 61-88.

28. Cano Aguilar, R. (1996): Lenguaje espontánteo y retórica epistolar en cartas de españoles a Indias. En Kotschi, T., Oesterreicher, W. y Zimmerman, K. (Eds.), El español hablado y la cultura oral en España e Hispanoamérica (pp. 375-404). Madrid/Fráncfort del Meno: Iberoamericana/Vervuert.

29. Cano Aguilar, Rafael (1995): Pragmática lingüística e historia de la lengua. Cauce: Revista Internacional de Filología, Comunicación y sus Didácticas, 18-19, pp. 703-718.

30. Carrera de la Red, M. (2012): Apropiación e imitación, procesos en la formación del registro periodístico colombiano del siglo XIX. Revista Internacional de Lingüistica Iberoamericana, 20, pp. 11-26.

31. Carrera de la Red, M. (2013): Análisis del discurso y sociopragmática histórica en un debate legal en la Cartagena de Indias del siglo XVIII. Intensificación y atenuación como recursos argumentales.

Pragmática Sociocultural, 1(1): pp. 11-45. DOI:

https://doi.org/10.1515/soprag-2012-0008

32. Carrera de la Red, M. y Álvarez A. (2004): Tratamientos y cortesía en la elaboración de fuentes documentales de la etapa fundacional de la provincia de Mérida (Venezuela), en Bravo, D. y Briz, A. (eds.): Pragmática sociocultural. Estudios sobre el discurso de cortesía en 
español (pp. 227-243): Barcelona: Ariel.

33. Carrera de la Red, M; y A. Herrán Santiago (2007): Oralidad en el universo de los discursos jurídico-administrativos en la Nueva Granada del siglo XVIII. En Cortés Rodríguez, L. (Coord.), Discurso y oralidad: homenaje al profesor José Jesús de Bustos Tovar (Vol. 1, pp. 333-349). Madrid: Arco Libros.

34. Company, C. (1993): Fonética novohispana a fines del siglo XVII. Anuario de Letras, 31, pp. 557-575.

35. Conde Silvestre, J. C. (2007): Sociolingüistica histórica. Madrid: Gredos.

36. Cruz Volio, M. G. (2017): Actos de habla y modulación discursiva en español medieval. Representaciones de (des)cortesía verbal histórica. Fráncfort del Meno: Peter Lang. DOI: https://doi.org/10.3726/b11018

37. Culpeper, J. y M. Kytö (1999): Modifying pragmatic force hedges in Early Modern English dialogues. En Jucker, A., Lebsanft, F. y Fritz, G. (Eds.), Historical Dialogue Analysis (pp. 293-312).

Ámsterdam/Filadelfia: John Benjamins. DOI: https://doi.org/10.1075/pbns.66.12cul

38. Eberenz, R. (2000): El español en el otoño de la Edad Media. Sobre el artículo y los pronombres, Madrid, Gredos.

39. Elias, N. (1994): The civilizing process. Oxford: Blackwell.

40. Elizaincín, A. y Groppi, M. (1991): La correspondencia familiar como documento para la lingüistica histórica. En Luna Traill, E. (Ed.), Scripta Philologica in honorem J. M. Lope Blanch (pp. 271-284): México D. F.: Universidad Nacional Autónoma de México.

41. Enrique-Arias, A. (2012): Dos problemas en el uso de corpus diacrónicos del español: perspectiva y comparabilidad, Scriptum Digital, 1, pp. 85-106.

42. Faya Cerqueiro, F. y Vila Carneiro, Z. (2014): Ampliando horizontes de investigación a través de la cooperación interdisciplinaria en Filología: el caso de la pragmática histórica, e-Scripta Románica, 1 , pp. 55-74. DOI: https://doi.org/10.18778/2392-0718.01.07

43. Fernández Alcaide, M. (2009): Cartas de particulares en Indias del siglo XVI. Madrid: Iberoamericana. DOI: https://doi.org/10.31819/9783964563866

44. Fernández Lávaque, A. M. (2005): Estudio sociohistórico de un proceso de cambio lingüístico. Salta: Universidad Nacional de Salta/Universidad de Buenos Aires.

45. Fitzmaurice, S. M. (2002): The Familiar Letter in Early Modern English. Ámsterdam: John Benjamins. DOI: https://doi.org/10.1075/pbns.95

46. Fontanella de Weinberg, M. B. (1989): El voseo bonaerense. Visión diacrónica. Bahía Blanca: Universidad Nacional del Sur.

47. Frago, J. A. (2002): Textos y normas. Comentarios lingüísticos. Madrid: Gredos.

48. Franco Figueroa (2011): Cartas de mujeres en documentos americanos coloniales. Boletín de Filología, XLVI(2), pp. 59-84. DOI: https://doi.org/10.4067/S0718-93032011000200003

49. Frank, B. (2011): Aufforderung im Französischen Ein Beitrag zur 
Geschichte sprachlicher Höflichkeit (Beihefte zur Zeitschrift für romanische Philologie 358), Berlín: Mouton de Gruyter. DOI: https://doi.org/10.1515/9783110235586

50. Fuentes Rodríguez, C. (2010): La gramática de la cortesía en español/LE. Madrid, Arco Libros.

51. Gancedo Ruiz, M. (2016). El texto dramático literario como corpus para el análisis histórico de las actividades de imagen. Textos en Proceso, 2(1), pp. 162-173. DOI: https://doi.org/10.17710/tep.2016.2.1.8gancedoruiz

52. Gancedo Ruiz, M. (2018): Una primera aproximación al análisis diacrónico de la atenuación y la imagen en diálogos madre-hijo en el teatro español en los siglos XIX y XX. ELUA, Anexo 4 (Ejemplar dedicado a Estudios de atenuación en el discurso, coordinado por García Ramón, A. y Soler Bonafont, M. A.), pp. 157-178. DOI: https://doi.org/10.14198/ELUA2018.Anex04.09

53. Gancedo Ruiz, M. (2019): Evolución de la imagen de rol familiar en el teatro de finales del siglo XIX a mitad del XX. Su manifestación en la atenuación e intensificación de los actos directivos. (Tesis doctoral). Universidad de Valencia. Recuperado de: http://hdl.handle.net/10550/69590

54. García Aguiar, L. C. (2012): El sistema de tratamientos en las Novelas Ejemplares de Cervantes. En Mortero Cartelle, E. y C. Manzano Rovira (Eds.), Actas del VIII Congreso Internacional de Historia de la Lengua Española (Vol. 2, pp. 2107-2178). Santiago de Compostela: Meubook/Asociación de Historia de la Lengua Española.

55. García Godoy, M. T. (2002): Notas sobre el leísmo en la historia del español de Andalucía (siglo XVIII): En Echenique, M. T. y Sánchez, J. (Eds.): Actas del $V$ Congreso Internacional de Historia de la Lengua Española (Vol. 1, pp. 645-656). Madrid: Gredos.

56. García Godoy, M. T. (2010): El tratamiento a los progenitores en el español peninsular (siglo XIX). Contraste de dos variedades geográficas. En Hummel, M., Kluge, B. y Vázquez Laslop, M. E., Formas y fórmulas de tratamiento en el mundo hispánico (pp. 595618). México, D. F./Graz: El Colegio de México, Centro de Estudios Lingüísticos y Literarios/Karl Franzens Universität.

57. García Godoy, M. T. (2012a): Introducción. En García Godoy, M. T. (Ed.), El español del siglo XVIII. Cambios diacrónicos en el primer español moderno. Berna: Peter Lang. DOI: https://doi.org/10.3726/978-3-0351-0388-5

58. García Godoy, M. T. (2012b): El tratamiento de merced en el español del siglo XVIII. En García Godoy, M. T. (Ed.), El español del siglo XVIII. Cambios diacrónicos en el primer español moderno (pp. 109-150). Berna: Peter Lang. DOI: https://doi.org/10.3726/978-3-0351-0388-5

59. García Mouton, P. (1999a): Cómo hablan las mujeres. Madrid, Arco Libros.

60. García Mouton, P. (1999b): Tratamientos en las cartas de Indias. En Forastieri Braschi, E., Cardona, J., López Morales, H. y Morales de Walters, A. (Coord.), Estudios de lingüistica hispánica: homenaje a María Vaquero (pp. 263-276). Puerto Rico: Universidad de Puerto Rico.

61. García Vizcaíno, M. L. (2008), Enseñanza de la cortesía verbal a 
través de la traducción. En Briz Gómez, A. et al. (Eds.), Cortesía y conversación: de lo escrito al oral, III Coloquio internacional del programa EDICE (pp. 692-710), Valencia: Universitat de Valencia.

62. Goméz Seibane, S. (2004): Uso de los pronombres átonos de tercera persona en guipuzcoanos emigrados a Indias en el siglo XVIII. Res Diachronicae Virtual, 3, pp. 39-51.

63. Gutiérrez Ordóñez, S. (2006), Ejercitarás la competencia pragmática. En Álvarez, A. et al. (Eds.), La competencia pragmática y la enseñanza del español como lengua extranjera. Actas del XVI Congreso Internacional de ASELE (pp. 25-44). Oviedo: Servicio de Publicaciones de la Universidad de Oviedo.

64. Hamad Zahonero, N. (2015): Tratamientos nominales en los siglos XV y XVI. (Tesis Doctoral): Universidad Complutense de Madrid. Recuperado de: https://eprints.ucm.es/39781/1/ T37903.pdf

65. Hammermüller, G. (2010): Evolución de las formas de tratamiento del español medieval hasta el siglo XVI. En Hummel, M., Kluge, B. y Vázquez Laslop, M. E., Formas y fórmulas de tratamiento en el mundo hispánico (pp. 507-529). México, D. F./Graz: El Colegio de México, Centro de Estudios Lingüísticos y Literarios/Karl Franzens Universität.

66. Haverkate, H. (1994): La cortesía verbal. Estudio pragmalingüístico. Madrid: Gredos.

67. Haverkate, H. (2001): Cortesía y descortesía en los diálogos del Quijote. Análisis de la representación de las imágenes positiva y negativa de los protagonistas. Oralia, 4, pp. 129-148.

68. Held, G. (2005a): Der Einfluss von Höflichkeit auf die mittelalterliche Briefkunst - exemplarische Überlegungen zur Entwicklung von Textstruktur und Syntax vom dictamen zur freien Briefpraxis. En Schrott, A. y Völker, H. (Eds.): Historische Pragmatik und historische Varietätenlinguistik in den romanischen Sprachen (pp. 45-62). Göttingen: Universitätsverlag Göttingen.

69. Held, G. (2010): Supplica la mia parvidade... Petitions in medieval society-a matter of ritualized politeness?. Journal of Historical Pragmatics, 11(2), pp. 194-218. DOI: https://doi.org/10.1075/jhp.11.2.02hel

70. Herrero Ruiz De Loizaga, F. J. (1999): El coloquio en el siglo XVI: cortesía, tratamiento y vocativos en la Segunda Celestina de Feliciano de Silva, Oralia, 2, pp. 221-240.

71. Herrero Ruiz De Loizaga, F. J. (2007): El insulto en la comedia celestinesca. En Cortés Rodríguez, L., Bañón, A. M., Espejo, M. M. y Muñío, J. L. (Coords.), Discurso y oralidad: homenaje al profesor José Jesús de Bustos Tovar (Anejo 3 de Oralia) (Vol. 1, pp. 349-365). Madrid, Arco Libros,

72. Herrero Ruiz De Loizaga, F. J. (2013): El insulto en las obras dialogadas de los siglos XVI y XVII. En Pérez-Salazar, C., Tabernero Sala, R. y Usunáriz Garayoa, J. M. (Coords.), Los poderes de la palabra: el improperio en la cultura hispánica del Siglo de Oro (pp. 149-173). Nueva York: Peter Lang.

73. Iglesias Recuero, S. (2010): Aportación a la historia de la cortesía. Las peticiones en el siglo XVI, en Orletti, F. y Mariottini, L. (Eds.), (Des)cortesía en español: espacios teóricos y metodológicos para su 
estudio (pp. 369-396). Università degli Studi Roma Trè/Programa EDICE/Universidad de Estocolmo.

74. Iglesias Recuero, S. (2016): Otra cara de la pragmática histórica: la historia de los actos de habla en español. Peticiones y órdenes en las Novelas ejemplares de Cervantes. En López Serena, A. et al. (Dirs.): El español a través de los tiempos. Estudios ofrecidos a Rafael Cano (Vol. 2, 971-994). Sevilla: Editorial Universidad de Sevilla.

75. Iglesias Recuero, S. (2017): Mecanismos de atenuación en las peticiones: de ayer a hoy, LEA: Lingüistica Española Actual, 39(2), pp. 289-316.

76. Iglesias Recuero, S. (En prensa): Pragmática histórica: una breve historia de la expresión de peticiones y otros actos directivos en español. Ponencia plenaria pronunciada en el XI Congreso Internacional de Historia de la Lengua Española (Lima, 6-10 de agosto de 2018).

77. Isasi Martínez, C. (2012): Seseo vasco en el siglo XIX: más allá de las hipercaracterizaciones. En Ramírez Luengo, J. L. (Ed.). Por sendas ignoradas. Estudios sobre el español del siglo XIX (pp. 113-129). Lugo: Axac.

78. Jacobs, A., y A. H. Jucker. (1995): The historical perspective in pragmatics. En Jucker, A. H. (Ed.), Historical pragmatics. Pragmatic developments in the History of English (Pragmatics y Beyond New Series 35) (pp. 3-33). Ámsterdam/Filadelfia: John Benjamins. DOI: https://doi.org/10.1075/pbns.35.04jac

79. Jucker, A. H. (Ed.): (1995): Historical pragmatics. Pragmatic developments in the History of English (Pragmatics y Beyond New Series 35): Ámsterdam/Filadelfia: John Benjamins. DOI: https://doi.org/10.1075/pbns.35

80. Jucker, A. H. y Kopaczyk, J. (2017): Historical (Im)politeness, en Culpeper, J. et al. (Eds.): The Palgrave Handbook of Linguistic (Im)politeness (pp. 433-460), Londres, Palgrave-McMillan. DOI: https://doi.org/10.1057/978-1-137-37508-7_17

81. Jucker, A. H. y Taavitsainen, I. (Eds.) (2010): The Handbook of Historical Pragmatics, Berlín/Nueva York: Mouton de Gruyter. DOI: https://doi.org/10.1515/9783110214284

82. Kabatek, J. (2016): Lingüística de corpus y lingüistica histórica iberorrománica. Berlín: De Gruyter. DOI: https://doi.org/10.1515/9783110462357

83. King, J. (2010a): Ceremonia y cortesía en la literatura del Siglo de Oro: un estudio de las formas de tratamiento en español, En Hummel, M., Kluge, B. y Vázquez Laslop, M. E., Formas y fórmulas de tratamiento en el mundo hispánico (pp. 531-550). México, D. F./Graz: El Colegio de México, Centro de Estudios Lingüísticos y Literarios/Karl Franzens Universität.

84. King, J. (2010b): Pleas from the New World: The structure of directive head acts in Colonial Spanish familiar letters. Journal of Historical Pragmatics, 10, pp. 250-279. DOI: https://doi.org/10.1075/jhp.11.2.04kin

85. King, J. (2012): Early Modern Spanish Request Modifications as Politeness Strategies: Implications for the Study of Register, en Fernández Amaya, L. et al. (Eds.): New perspectives on 
(im)politeness and interpersonal communication (pp. 138-156). Cambridge, Cambridge Scholars Publishing.

86. Koch, P. y Oesterreicher, W. (1985): Sprache der Nahe? Sprache der Distanz. Mündlichkeit und Schriftlichkeit im Spannungsfeld von Sprachtheorie und Sprachgeschichte. Romanistisches Jahrbuch, 36, pp. 15-43.

87. Koch, P. y Oesterreicher, W. ([1990] 2007): Lengua hablada en la Romania: español, francés, italiano. Madrid: Gredos (Biblioteca Románica Hispánica, Estudios y ensayos, 448). Versión española de Araceli López Serena del original alemán Gesprochene Sprache in der Romania: Französisch, Italienisch, Spanisch, Tubinga: Niemeyer, 1990. DOI: https://doi.org/10.1515/9783111372914

88. Koch, P. y Oesterreicher, W. (2001): Langage parlé et langage écrit. En: Holtus, G., Metzeltin, M. y Schmitt, Chr. (Eds.), Lexikon der Romanistischen Linguistik (pp. 584-628). Tübingen, Niemeyer.

89. Koester, A. (2010): Building small specialised corpora. O'Keeffe, A. y Mccarthy, M. (Eds.): The Routledge Handbook of Corpus Linguistics (pp. 66-79): Oxford: Routledge.

90. Koike, A. (1992): Language and Social Relationship in Brazilian Portuguese. Austin: University of Texas Press.

91. Labov, W. (1972): Sociolinguistics Patterns. Filadelfia: Pennsylvania University Press. Traducción al español: Modelos sociolingüísticos. Madrid: Cátedra, 1983.

92. Landone, E. (2009a): Los marcadores del discurso y la cortesía verbal en español. Bérgamo: Peter Lang. DOI: https://doi.org/10.3726/978-3-0351-0103-4

93. Landone, E. (2009b): Reflexiones sobre la cortesía verbal en la enseñanza/ aprendizaje de ELE. Marco ELE, 8.

94. Lapesa Melgar, R. (2000), Personas gramaticales y tratamientos en español. En Cano Aguilar, R. y Echenique Elizondo, M. T. (Eds.), Estudios de morfosintaxis histórica del español (Vol. 2, pp. 311-345). Madrid, Gredos

95. Leal Abad, E. (2008): Configuraciones sintácticas y tradiciones textuales. Los diálogos medievales. Sevilla: Servicio de Publicaciones de la Universidad de Sevilla.

96. Leal Abad, E. (2011): La fuerza ilocutiva en los debates medievales castellanos de controversia y su plasmación lingüística. E-Spania, 6. Recuperado de: http://journals.openedition.org/e-spania/13833.

97. Leech, G. N. (2014): The pragmatics of politeness. Nueva York: Oxford University Press. DOI: https://doi.org/10.1093/acprof:oso/9780195341386.001.0001

98. Lope Blanch, J. M. (1985): El habla de Diego de Ordaz. Contribución a la historia del español americano. México D. F.: Universidad Nacional Autónoma de México. DOI: https://doi.org/10.24201/nrfh.v33i2.594

99. Macías Domínguez, A. M. (2016): Emociones sobre el papel, cartas de cariño: relaciones entre novios y desposados a través de sus cartas y billetes (Sevilla, siglo XVIII). En Candau Chacón, M. L. (Ed.) Las mujeres y las emociones en Europa y América. Siglos XVIII-XIX (pp. 93-120). Santander: Editorial de la Universidad de Cantabria. 
100. Martín Zorraquino, M. A. (2001): Marcadores del discurso y estrategias de cortesía verbal en español, en Montoya, M. I. (Ed.), La lengua española y su enseñanza (pp. 55-74). Granada: Universidad de Granada.

101. Martínez Pasamar, C. (2019): Fenómenos de covariación lingüística en cartas del siglo XIX: las estrategias de intensificación y otras dimensiones de la variación. En Castillo, M. y Díaz del Corral, E., (Eds.), Reescribiendo la historia de la lengua a partir de la edición de documentos (pp. 420-444). Berna: Peter Lang.

102. Martínez Pasamar, C. y Tabernero Sala, C. (2019): Reflexiones metodológicas sobre el tratamiento de la atenuación y la intensificación en corpus históricos: cartas privadas del siglo XIX. En González Ruiz, R., Loureda, Ó. y Olza, I. (Eds.) Lengua, cultura, discurso. Estudios ofrecidos al profesor Manuel Casado Velarde (pp. 429-445). Pamplona: EUNSA.

103. Medina Morales, F. (2004): Las formas nominales de tratamiento en el siglo de Oro. Aproximación sociolingüística. En Lobato, M. L. y Domínguez Matito, F. (Eds.), Memoria de la palabra. Actas del VI Congreso de la Asociación Internacional Siglo de Oro (Vol. 2, pp. 1329- 1342). Madrid: Iberoamericana,

104. Medina Morales, F. (2010): La metodología en los estudios sobre formas y fórmulas de tratamiento en español. En Hummel, M., Kluge, B. y Vázquez Laslop, M. E., Formas y fórmulas de tratamiento en el mundo hispánico (pp. 21-56). México, D. F./Graz: El Colegio de México, Centro de Estudios Lingüísticos y Literarios/Karl Franzens Universität.

105.Moreno Fernández, F. (1998): Principios de sociolingüistica y sociología del lenguaje. Barcelona: Ariel.

106. Moreno González, M. C. (2002): La cortesía verbal en el Siglo de Oro: los actos de habla defectivos. En Echenique, M. T. y Sánchez Méndez, J. (Eds.), Actas del V Congreso Internacional de Historia de la Lengua Española (pp. 1347-1359). Madrid: Gredos.

107. Moreno González, Mํㅡ C. (2008): Análisis diacrónico de la cortesía verbal del español clásico al contemporáneo. En Briz, A., Hidalgo, A., Albelda, M., Contreras, J. y Hernández Flores, N. (Eds.): Cortesía y conversación: de lo escrito a lo oral (410-418). Valencia/Estocolmo: Universidad de Valencia/Programa EDICE.

108.Muir, E. (1997): Ritual in Early Modern Europe. Cambridge: Cambridge University Press.

109. Murillo, J. (Ed.) (2005): Actos de habla y cortesía en distintas variedades del español: Perspectivas teóricas y metodológicas. Actas del II coloquio internacional del programa EDICE. Estocolmo/Costa Rica: Programa EDICE/Universidad de Costa Rica. Recuperado de: http://edice.org/

110. Narbona Jiménez, A. (1989): Sintaxis española: nuevos y viejos enfoques, Barcelona: Ariel.

111. Níkleva, D. G. (2009): La cortesía en la enseñanza del español como lengua extranjera. Recursos no verbales: aplicación de los códigos semióticos. Marco ELE, 9.

112. Oesterreicher, W. (2004): Textos entre la inmediatez y distancia comunicativas. El problema de lo hablado escrito en el siglo de Oro. 
En Cano, R., Historia de la lengua española (739-769). Barcelona: Ariel.

113. Otte, E. (1988): Cartas privadas de emigrantes a Indias. Sevilla: Escuela de Estudios Hispano-Americanos.

114. Palander-Collin, M. y Nevala, M. (Eds.) (2005): Letters and Letter Writing. European Journal of English Studies, 9(1). DOI: https://doi.org/10.1080/13825570500067903

115. Pedroviejo Esteruelas, J. M. (2003): Análisis de las fórmulas de tratamiento en los pasos de Lope de Rueda. Artifara, 3.

116. Pedroviejo Esteruelas, J. M. (2012): Las formas de tratamiento pronominales y verbales referentes a la segunda persona del singular y las fórmulas de tratamiento nominales en entremeses del siglo XVII. Hipertexto, 15, pp. 156-80.

117. Pérez-Cordón, C. (2008): Un sencillo acercamiento a la pragmática. RedELE, 14.

118. Placencia, M. E. y García, C. (2011): Estudios de variación pragmática (sub)regional en español: visión panorámica. En García, C. y Placencia, M. E. (Eds.), Estudios de variación pragmática en español (pp. 29-54). Buenos Aires: Dunken.

119. Pons Rodríguez, L. y Octavio de Toledo y Huerta, A. S. (2016): Queja politica y escritura epistolar durante la Guerra de Independencia: documentación de la Junta Suprema Central en el AHN. Selección, edición y estudio lingüístico. Madrid: Universidad de Alcalá.

120.Pountain, C. J. (2009): Variation in Address Forms in 16th-Century Spanish Prose Drama. Reinheimer-Rîpeanu, S. (Ed.), Studia Lingvistica in honorem Mariae Manoliu (282-293), Sanda. Bucarest, Editura Universității din București.

121. Ramírez Luengo, J. L. (2006): Para la historia de si tendría: el pretérito de subjuntivo en la Guipúzcoa del siglo XVIII. Oihenart, 21 (Lingüística Vasco-Románica/Euskal Erromantze Linguistika), pp. 395-408.

122. Ramírez Luengo, J. L. (2010): El español del occidente de Bolivia en la época de las Independencias: notas fonético-fonológicas. Boletín de Filología de la Universidad de Chile, 45(1), pp. 159-174. DOI: https://doi.org/10.4067/S0718-93032010000100006

123. Ramírez Luengo, J. L. (2013): Una descripción del español de mediados del siglo xviii. Edición y estudio de las cartas de $M$. Martierena del Barranco (1757-1763). Lugo: Axac.

124. Ramírez Luengo, J. L. (2016): Documentación de archivo e historia de la lengua: una reflexión desde el caso colombiano. Revista lingüistica y literatura, 70, pp. 87-117. DOI: https://doi.org/10.17533/udea.lyl.n70a04

125. Ridruejo, E. (2007): Problemas metodológicos en pragmática histórica. En Trotter, D. (Ed.), Actes du XXIV Congrès International de Linguistique et Philologie Romanes (Vol. 3, pp. 533-548). Tübingen Max Niemeyer Verlag.

126. Rígano, M. E. (2000): Fórmulas de tratamiento y cortesía en las relaciones amorosas de la novela de caballería (siglo XVI). Cuadernos del Sur. Letras, 30, pp. 139-166.

127. Rivarola, J. L. (2000): El español de América en su historia. 
Valladolid: Universidad de Valladolid.

128. Romaine, S. (1982), Socio Historical linguistics: its status and methodology. Cambridge, Cambridge UP. DOI: https://doi.org/10.1017/CBO9780511720130

129. Rouvillois, F. (2008): Histoire de la politesse de 1789 à nos jours. París: Flammarion. DOI: https://doi.org/10.14375/NP.9782081217805

130.Salmon, V. (1987): Sentence structures in colloquial Shakespearean English. En Salmon, V. y Burness, E. (Eds.), A reader in the language of Shakespearean Drama (pp. 265-300), Ámsterdam: John Benjamins. DOI: https://doi.org/10.1075/sihols.35.29sal

131. Sánchez Castro, M. (2007). Contrastes. Español para hablantes de alemán. Madrid: SGEL. DOI: https://doi.org/10.24310/Contrastescontrastes.v12i0.1442

132. Schrott, A. (2000): “¿Quí los podrié contar? Interrogative acts in the Cantar de mio Cid: Some examples form Old Spanish on asking questions. Journal of Historical Pragmatics, 1(2), pp. 263-299. DOI: https://doi.org/10.1075/jhp.1.2.06sch

133. Stein, D. (1985): Perspectives on historical pragmatics. Folia Linguistica Historica, 6(1), pp. 347-355. DOI: https://doi.org/10.1515/flih.1985.6.2.347

134. Taavitsainen, I., y Fitzmaurice, S. (2007). Historical pragmatics: What it is and how to do it. En Susan M. Fitzmaurice and Irma Taavitsainen (Eds.), Methodological issues in historical pragmatics (pp. 11-36), Berlín: Mouton de Gruyter. DOI: https://doi.org/10.1515/9783110197822.107

135. Tabernero Sala, C. (2010): Injurias, maldiciones y juramentos en la lengua española del siglo XVIII. Revista de lexicografía, 16, pp. 101122. DOI: https://doi.org/10.17979/rlex.2010.16.0.3808

136. Tabernero Sala, C. (2019): Fórmulas de cortesía y mecanismos de atenuación en la retórica epistolar del siglo XIX. En Carrillo, M. y Diez de Corral, E. (Eds.), Reescribiendo la historia de la lengua a partir de la edición de documentos (pp. 391-419). Berna: Peter Lang.

137. Tabernero Sala, C. (2020): Larga he sido pero no cuanto deseo": las mujeres como redactoras de cartas en la cultura escrita de la Edad Moderna. En Stefan, S. A. (Ed.), Curiosidad y censura en la Edad Moderna (pp. 5-36). Bucarest: Servicio de Publicaciones de la Universidad de Bucarest.

138. Wesch, A. (1996): Tradiciones discursivas en documentos indianos del S.XVI: sobre la estructuración del mandato en ordenanzas e instrucciones", en Alonso González, A. et al. (Coords.): Actas del III Congreso Internacional de Historia de la Lengua Española (Vol. 1, pp. 955-967), Madrid: Arco Libros.

139.Zamora, F. J. (2014): Actividades de imagen en textos narrativos. Pragmática Sociocultural, 1(2), pp. 75-198. 